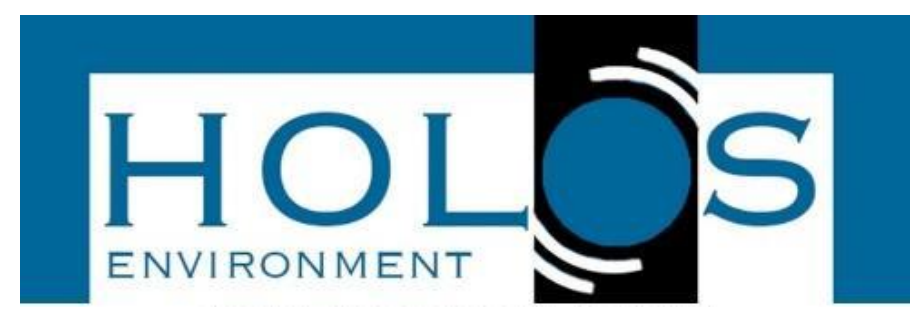

\title{
MODELO ÁREA-VOLUME PARA A REPRESA GUARAPIRANGA EMPREGANDO O ÍNDICE NDWI
}

\section{AREA-VOLUME MODEL FOR GUARAPIRANGA RESERVOIR USING NDWI INDEX}

\author{
Caroline Favoreto da Cunha1'; Sabrina Brandão Cardosoํ; Elias Hideo Teramoto; \\ Hung Kiang Chang ${ }^{2}$
}

Artigo recebido em: 23/01/2020 e aceito para publicação em: 17/02/2020.

DOI: http://dx.doi.org/10.14295/holos.v20i1.12370

\begin{abstract}
Resumo: As represas representam uma importante fonte de água para fins de abastecimento urbano. A variação do volume de água armazenada nesses reservatórios pode ser estimada a partir da relação empírica área-volume, na qual a área do reservatório ocupada por água pode ser calculada a partir de técnicas de sensoriamento remoto, destacando-se aquelas estimadas a partir do emprego do cálculo Índice de Diferença Normalizada da Água (NDWI). Para a construção do modelo área-volume da Represa Guarapiranga, uma das principais fontes de abastecimento de água na Região Metropolitana de São Paulo, 21 imagens com o índice NDWI foram produzidas com base em imagens de satélite Landsat-8 OLI entre janeiro de 2013 e janeiro de 2020. A análise de regressão da área coberta por água e o volume efetivamente mensurado na Represa de Guarapiranga, permitiram a elaboração de um modelo empírico área-volume com o coeficiente de determinação $\left(R^{2}\right)$ de 0,79 , o que demonstra a viabilidade do emprego desta abordagem para estimativas realistas do volume de água armazenada.
\end{abstract}

Palavras-chave: Represa de Guarapiranga. NDWI. relação área-volume do reservatório. Landsat-8 OLI.

\begin{abstract}
Dams represent an important source of water for supply purposes of urban areas. The water volume variation stored in these reservoir can be estimated from empirical area-volume relationship, in which the area of the reservoir filled by water can be derived from remote sensing techniques, emphasizing those derived from the use of the Normalized Water Difference Index (NDWI) calculation. For the establishment of the area-volume model at the Guarapiranga Reservoir, one of the main sources of water supply in the Metropolitan Region of São Paulo, 21 images with the NDWI index were produced using Landsat-8 OLI satellite images between January 2015 and January 2020. The regression analysis of the area covered by water and the volume measured at the Guarapiranga Dam, allowed the development of an empirical area-volume model with $\mathrm{R}^{2}$ of 0.79 , demonstrating the feasibility of using this approach for realistic volume estimates. of stored water.
\end{abstract}

Keywords: Guarapiranga Reservoir. NDWI. Reservoir area-volume ratio. Landsat-8 OLI.

\footnotetext{
1 Universidade Estadual Paulista Júlio de Mesquita Filho (UNESP), Campus Rio Claro, SP. E-mails: (caroline.favoreto@unesp.br, sb.cardoso@unesp.br, elias.hideo-teramoto@unesp.br)

${ }^{2}$ DGA - Departamento de Geologia Aplicada (UNESP), Campus de Rio Claro, SP. LEBAC - Laboratório de Estudo de Bacias, Unesp - Campus de Rio Claro, SP. E-mail: (chang.hung-kiang@unesp.br)
} 


\section{INTRODUÇÃO}

Do volume total de água disponível no planeta Terra, 97,5\%\% é salgada, ocupando mares e oceanos, e apenas 2,5\% é doce, se distribuindo como geleiras, águas subterrâneas, rios e lagos (SHIKLOMANOV, 1993). Rios e lagos juntos perfazem somente $0,3 \%$ do volume total de água doce no planeta (SHIKLOMANOV, 1993). A despeito dos reservatórios representarem uma fração ínfima da água doce disponível no planeta, os reservatórios possuem elevada importância para irrigação, produção de energia e abastecimento público. A importância dos reservatórios experimentou forte crescimento nas últimas décadas (CHAO et al., 2008). Chao et al. (2008) estimou em aproximadamente em $10.800 \mathrm{~km}^{3} \mathrm{o}$ incremento do volume de água armazenadas em reservatórios desde o ano de 1990. A despeito da maior parte dos reservatórios construídos na atualidade visarem a operação de usinas hidroelétricas (MCDONALD et al., 2009; ZARFL et al., 2015; TIMPE e KAPLAN, 2017), as grandes represas ainda representam uma importante fonte de água para fins de abastecimento urbano.

Wisser et al. (2013) definem o armazenamento de água em reservatórios como um dos principais mecanismos para lidar com a variabilidade da oferta e demanda de água. Ainda de acordo com esses autores, a despeito do expressivo incremento do volume de água armazenadas em reservatórios, este não acompanhou o crescimento populacional. Para exemplificar, entre os anos de 1990 e 2010, a população global aumentou cerca de $30 \%$, enquanto a capacidade dos reservatórios instalados experimentou um incremento de apenas 9\%, isto é, de 5497 para $5990 \mathrm{~km}^{3}$ (WISSER et al., 2013).O incremento da demanda de água, decorrente do crescimento populacional, exerce fortes pressões sobre os recursos hídricos, fazendo com que seja super-explotado.

Além da ação antrópica, a quantidade de água armazenada em reservatórios é sujeita a variações sazonais, decorrentes da alternância de estações secas e chuvosas. Como demonstrado por Haddeland et al. (2006), o volume de água pode apresentar oscilações sazonais de $30 \%$ em função de variações no influxo de água dentro do reservatório. Em razão destas variações, o monitoramento dos volumes dos reservatórios é essencialmente importante para regular seu uso. O método áreavolume, utilizado para estimar o volume de água em reservatórios, se baseia na relação entre área e volume, em que a área da lâmina d'água permite estimar o 
volume de água no reservatório (LEHNER e DÖLL, 2004; RAN e LU, 2012; VAN BEMMELEN et al., 2016; CAl et al., 2016).

Abordagens distintas, que se apoiaram no emprego de técnicas de sensoriamento remoto para delimitação de reservatórios foram propostas por diversos trabalhos, destacando Gupta e Banerji (1998), Nellis et al. (1998), Gao et al. (2012), Lu et al. (2013), Cai et al. (2016), Deutsch e Alameddine (2019). Na atualidade, a maioria dos métodos para identificação e delimitação dos corpos d'água, empregando técnicas de sensoriamento remoto, são intermediadas pelo cálculo do Índice de Diferença Normalizada da Água (NDWI), desenvolvido por McFeeters (1996) ou pelo Índice Modificado da Diferença Normalizada de Água (MNDWI), desenvolvida por Xu (2006). O NDWI e o MNDWI baseiam-se na diferença normalizada da absorção e reflexão da luz entre a água e outros alvos em diferentes faixas de frequência (MCFEETERS, 1996; XU, 2006).

A água captada da Represa Guarapiranga responde pelo abastecimento de grande parte da Grande São Paulo. De acordo com a SABESP (2016), o volume de água captado para fins de abastecimento em 2013 foi de 13,68 m³/s, atendendo a 4 milhões de pessoas na Região Metropolitana de São Paulo (RMSP). Na crise hídrica registrada entre os anos de 2014 e 2015, a Represa de Guarapiranga atingiu seus níveis mais baixos, com as menores vazões registradas em 85 anos (SABESP, 2015). Nesse período, o abastecimento operou com apenas $31,36 \%$ da capacidade de armazenamento, criando uma forte crise no abastecimento de água na região mais rica e populosa do território brasileiro. Face ao severo cenário adverso apresentado, fica evidente a necessidade da adoção de estratégias para a correta gestão adequada dos recursos hídricos, como monitoramento dos volumes de água armazenados nos reservatórios. Por essa razão, estratégias para determinação dos volumes de reservatórios são especialmente relevantes. Este fato evidenciou a necessidade da devida gestão dos recursos hídricos, que exige o monitoramento dos volumes de água armazenados no reservatório. Diante da importância estratégica da Represa Guarapiranga, o presente trabalho teve por objetivo um modelo área-volume para esse reservatório, empregando imagens de satélite de média resolução Landsat-8 OLI. 


\section{MATERIAIS E MÉTODOS}

\section{1 Área de Estudo}

A Represa de Guarapiranga está inserida na Bacia do Alto Tietê e atua como um reservatório para o abastecimento de água potável para cerca de 4,9 milhões de pessoas da zona sul e sudeste de São Paulo. Situada a sudoeste da RMSP, na divisa entre os municípios de São Paulo (Zona Sul), Itapecerica da Serra e Embu-Guaçu (Figura 1), a represa é receptora das águas dos rios Embu-Mirim, Embu-Guaçu, Santa Rita, Vermelho, Ribeirão Itaim, Capivari e Parelheiros, e estima-se a chegada de $13.193 \mathrm{~m}^{3} / \mathrm{s}$ de água desses afluentes, além de $0,465 \mathrm{~m}^{3} / \mathrm{s}$ de esgoto doméstico (MANCUSO, 1992).
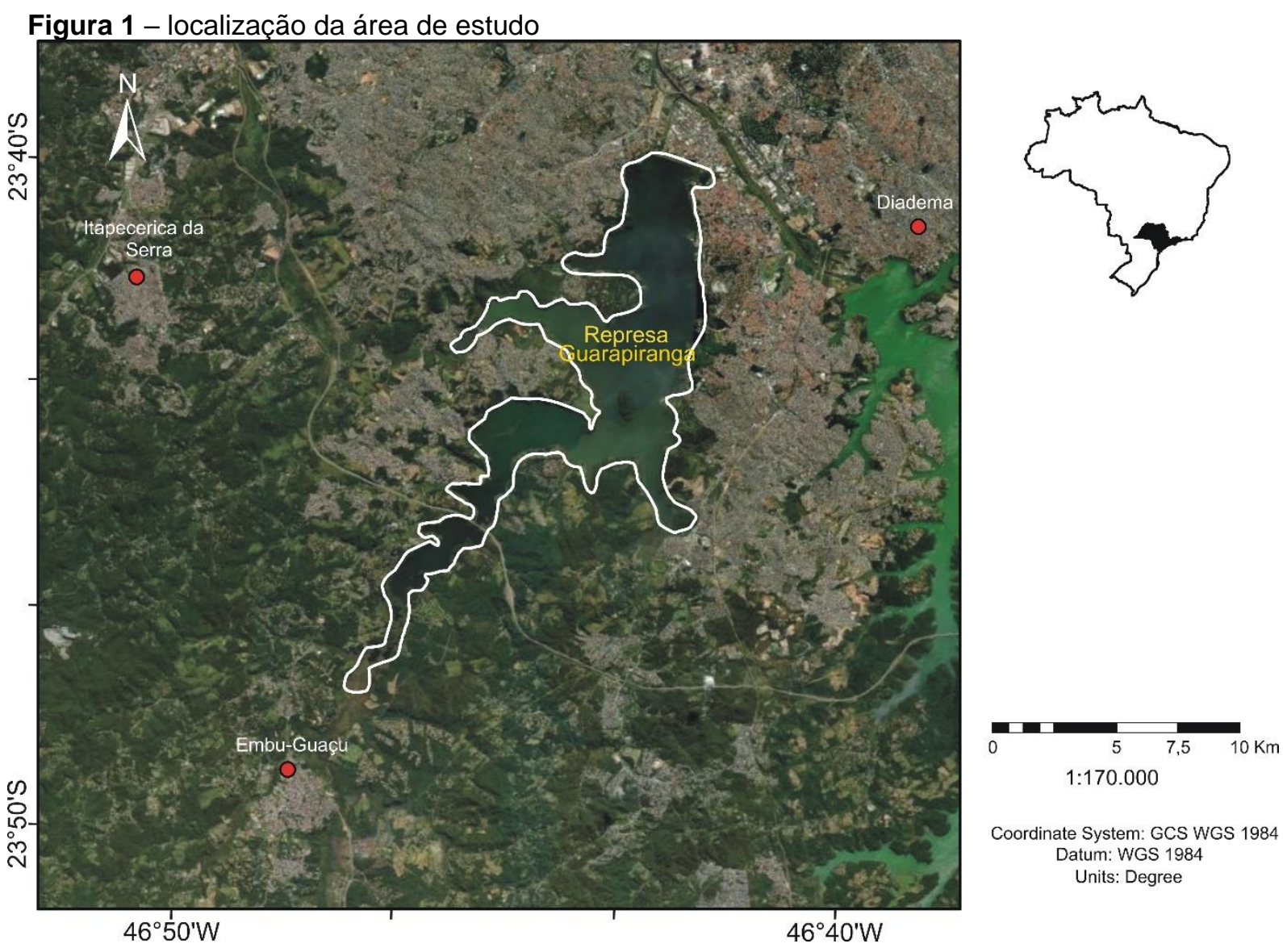

Coordinate System: GCS WGS 1984 Datum: WGS 1984 Units: Degree

Fonte: Elaborado pelos autores 


\subsection{Variações do Volume de Água na Represa Guarapiranga}

Integrante do segundo maior sistema de abastecimento da RMSP - Sistema Guarapiranga, a capacidade de armazenamento da Represa Guarapiranga é de aproximadamente $171,2 \mathrm{Km}^{3}$ (SABESP, 2016). Tendo em vista a ampla variabilidade da área inundada pela Represa Guarapiranga, devido ao volume de água extraído e à alternância de períodos secos e chuvosos, o nível de água tende a seguir a média pluviométrica (Figura 2). No entanto, eventos atípicos na quantidade de chuvas geram conflitos e deixam em alerta a gestão pública. A estação chuvosa média encontra-se no início de novembro e se encerra no início de abril, no entanto, a análise dos anos de 2013/2014 e 2014/2015, revela a ocorrência de inícios tardios e términos antecipados dos períodos de chuva (CUSTÓDIO, 2015). A Figura 2 a existência de um descompasso de aproximadamente um mês entre o início do período chuvoso e a subida do volume de água armazenada no reservatório.

Figura 2 - Variações do volume de água na Represa Guarapiranga e dos índices pluviométricos diários na região, entre os anos de 2015 e 2020.

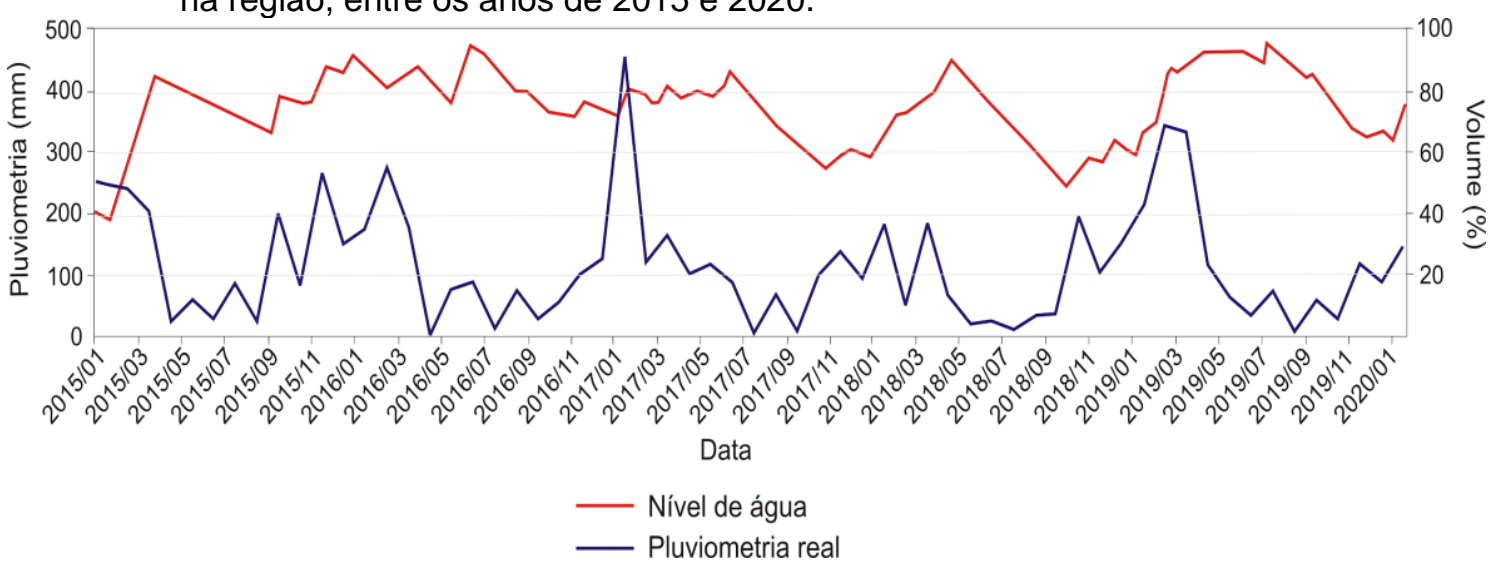

Fonte: Elaborado pelos autores

\subsection{Imagens Utilizadas e Dados}

Os dados espectrais de reflexão de superfície do Satélite Landsat 8-OLI possuem resolução temporal de 16 dias e espacial de $30 \mathrm{~m}$, composto por 9 bandas que variam em comprimento de ondas (Tabela 1 ). 
Tabela 1 - Relação das bandas, comprimentos de onda e resolução espacial do satélite landsat-8 oli

\begin{tabular}{ccc}
\hline Banda & $\begin{array}{c}\text { Comprimento de } \\
\text { onda }(\mathbf{n m})\end{array}$ & $\begin{array}{c}\text { Resolução } \\
\text { Espacial (m) }\end{array}$ \\
\hline B1 - Azul costeiro & $430-450$ & 30 \\
B2 - Azul & $450-510$ & 30 \\
B3 - Verde & $530-590$ & 30 \\
B4 - Vermelho & $640-670$ & 30 \\
B5 - Infravermelho & & \\
$\quad$ próximo & $850-880$ & 30 \\
B6 - Infravermelho & & \\
$\quad$ médio 1 & $1570-1650$ & 30 \\
B7 - Infravermelho \\
$\quad$ médio 2 & $2110-2290$ & 30 \\
B8 - Pancromática & $500-680$ & 15 \\
B9 - Cirrus & $1360-1380$ & 30 \\
\hline
\end{tabular}

No total, 21 imagens compreendendo um período situado entre abril de 2013 e dezembro de 2019 foram baixadas do United States Geological Survey (USGS) (http://landsat.usgs.gov/). Foram selecionadas imagens com ausência total de nuvens sobre os reservatórios, pois a presença destas impõe fortes limitações à metodologia empregada no presente trabalho, tendo em vista que sua presença impede a detecção de água em superfície. Nos períodos chuvosos (novembro a março), as imagens apresentam, invariavelmente, extensa cobertura por nuvens, impossibilitando a análise neste período, o que gera forte deficiência de informações.

\subsection{Cálculo da área do reservatório}

Como os reflexos da água da faixa visível para a faixa do infravermelho são gradualmente enfraquecidos, a água de superfície em uma imagem pode ser delineada com os índices NDWI e MNDWI pelo contraste entre o comprimento de onda visível e os comprimentos de onda do infravermelho próximo e de onda curta.

O Índice de diferença normalizada da água (NDWI) representa um método desenvolvido para delinear corpos d'água em superfície a partir de imagens digitais obtidas por sensoriamento remoto. De acordo com McFeeters (1996), o NDWI utiliza radiação refletida no infravermelho próximo e luz verde visível para a identificação de 
água e sua distinção em relação ao solo e à vegetação terrestre. O NDWI é calculado a partir da Equação 1.

$$
N D W I=\frac{\left(\rho_{\text {GREEN }}-\rho_{N I R}\right)}{\left(\rho_{\text {GREEN }}+\rho_{N I R}\right)}
$$

Onde $\rho_{\text {GREEN }}$ representa a banda do verde e $\rho_{N I R}$ a banda do infravermelho próximo. Essa equação gera valores de pixels que variam em escala de -1 a 1 , em que valores de $\mathrm{NDWI} \geq 0$ referem-se à água, e NDWI < 0 , ao solo e vegetação.

Para evitar a quantificação da água em corpos d'água não pertencentes à Represa de Guarapiranga, todos os rasters NDWI foram recortados próximos ao contorno da represa. Posteriormente, as rasters foram convertidos em arquivo shapefile de pontos e os valores calculados de NDWI foram classificados em ordem crescente para facilitar a identificação dos valores de NDWI entre 0 e 1, intervalo esse indicativo da ocorrência de áreas cobertas por água. A área do reservatório $(A)$ foi calculada a partir da multiplicação do número de pixels classificados como água pela área do pixel da imagem Landsat, isto é $900 \mathrm{~m}^{2}$ (Equação 2).

$A=\sum_{i=1}^{n} P_{i} * 900$

Onde $\mathrm{n}$ representa o número de pixels classificadas como água e $P_{i}$ um pixel individual classificado como água.

\subsection{Modelo Empírico para Estimativas do Volume do Reservatório}

Como demonstrado por diversos trabalhos, incluindo Lehner e Döll (2004), Liebe et al. (2005), Ran e Lu (2012), van Bremmelen et al. (2016) e Cai et al. (2016), o volume de água armazenada em reservatórios está relacionado com a área de superfície, segundo um modelo de potência expressa na Equação 3.

$$
V=a \cdot A^{b}
$$

Onde $V$ é o volume de água armazenada $\left(\mathrm{L}^{3}\right)$, $\mathrm{A}$ é a área do corpo d'água $\left(\mathrm{L}^{2}\right)$, a e b são constantes obtidas a partir de regressão não-linear. 
Lehner et al. (2011) por meio da análise de 5824 reservatórios de grande porte ao redor do mundo, propuseram uma relação área-volume média global, expressa pela Equação 4, com $R^{2}$ de 0,80 .

$V=30,684 \cdot A^{0,978}$

A partir das estimativas da área do reservatório pelo cálculo do índice NDWI, foi realizada uma análise de regressão não-linear para avaliar a correlação entre os dados obtidos por sensoriamento remoto e as medidas volumétricas disponibilizadas pela Sabesp (http://mananciais.sabesp.com.br/), adotando a linha de regressão que melhor se ajustasse à disposição dos dados.

\section{RESULTADOS}

\subsection{Delimitação dos Corpos Hídricos com o Índice NDWI}

A partir das imagens nas bandas 3 e 5 do satélite Landsat-8 OLI e aplicandose a Equação 1, foram obtidos os mapas com a distribuição espacial dos índices NDWI. A Figura 3 apresenta dois cenários distintos da Represa de Guarapiranga, considerando o período de análise (abril 2013 a dezembro de 2019): um em que foi observada a área mínima do reservatório com água, em janeiro de 2015 (Figura 3A), e outro em que foi observada a área máxima do reservatório com água, em junho de 2019 (Figura 3B).

A delimitação da área coberta por água foi conduzida a partir da identificação dos pixels com valores entre o e 1, associado a áreas cobertas por água. Para evidenciar as fortes variações na área de reservatório coberta por água, a Figura 4 apresenta a sobreposição dos limites mínimo $\left(\mathrm{km}^{2}\right)$ e máximo $\left(\mathrm{Km}^{2}\right)$ registrados, respectivamente em janeiro de $2015\left(94 \mathrm{Km}^{2}\right)$ e junho de $2019\left(158 \mathrm{Km}^{2}\right)$. 
Figura 3 - Delimitação da área coberta por água na Represa de Guarapiranga gerada a partir do cálculo do índice NDWI: A) janeiro de 2015, quando foi registrado o menor volume de água no reservatório; B) junho de 2019, quando foi registrado o maior volume de água no reservatório. As áreas correspondentes à água (valor entre 0 e 1) são representadas com a cor azul.

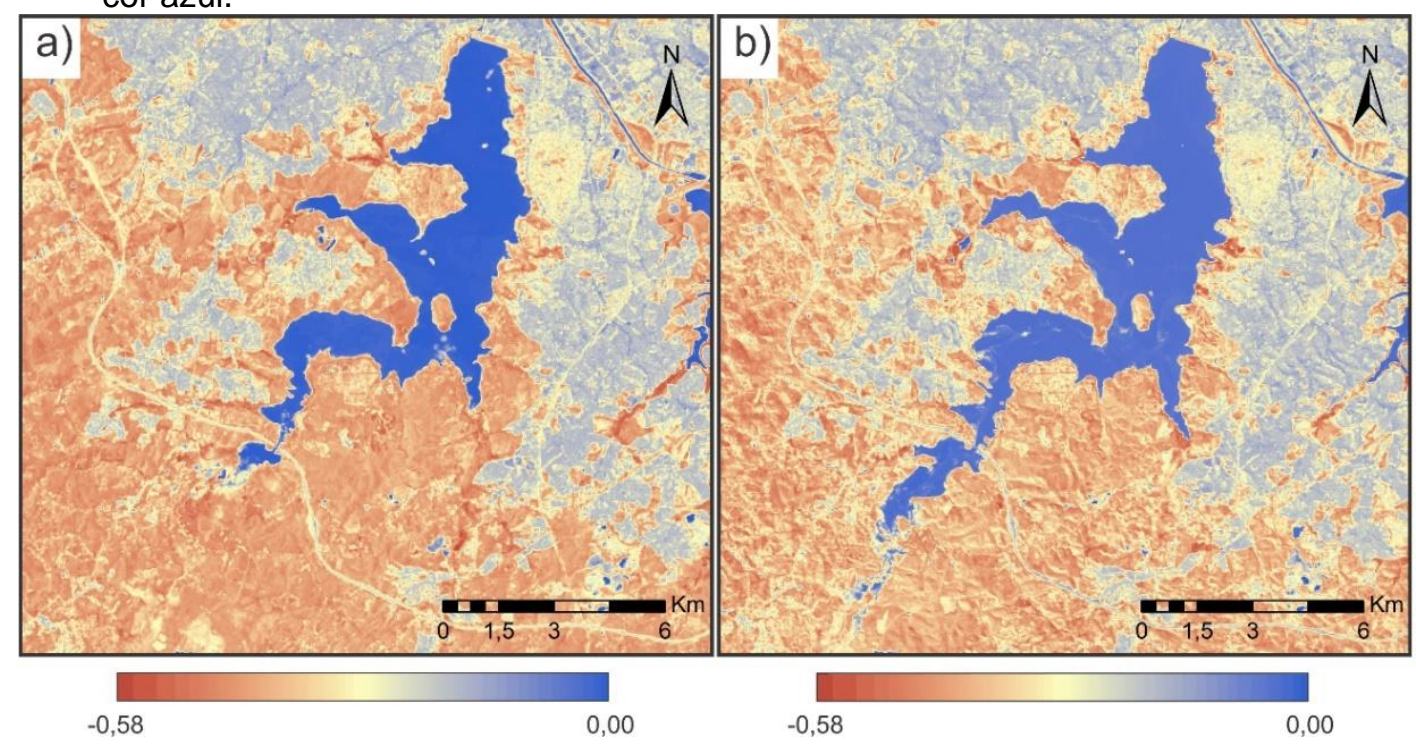

Fonte: Elaborado pelos autores

Figura 4 - Sobreposição da área inundada por água nos períodos de janeiro de 2015 (94 $\mathrm{Km}^{2}$ ) e junho de 2019 (158 $\left.\mathrm{Km}^{2}\right)$

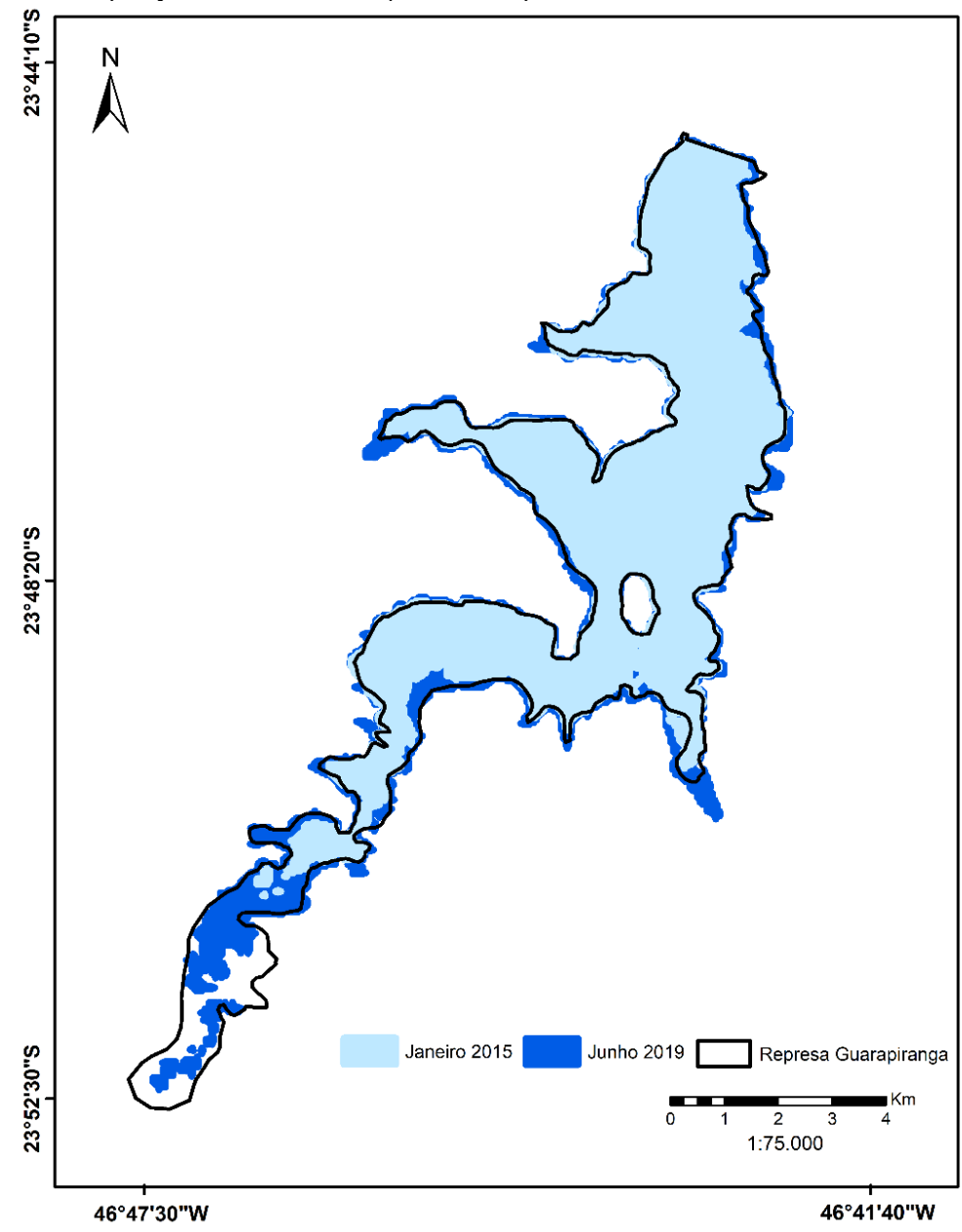

Fonte: Elaborado pelos autores 


\subsection{Relação empírica área e volume de água}

Os resultados gerados pelo processamento das imagens permitiram definir as extensões da área do reservatório cobertas por lâmina d'água (Tabela 2): essas áreas juntamente com os volumes obtidos junto a SABESP prestaram-se à geração do gráfico de regressão não-linear para a análise de correlação $\left(R^{2}\right)$. A análise de regressão não-linear foi ajustada a Equação 3 aos dados analisados e obtido o valor de $a$ igual a 0,0088 e $b$ igual a 3,0498, como exposto na Figura 5 .

Tabela 2 - Data da imagem processada, área da cobertura da lâmina d'água do reservatório estimada pelo NDWI e volume de água na Represa Guarapiranga

\begin{tabular}{ccc}
\hline \hline Data & Área $\mathbf{~ m}^{2}$ & $\begin{array}{c}\text { Volume } \\
\left(\mathbf{K m}^{3}\right)\end{array}$ \\
\hline \hline $26 / 04 / 2013$ & 23,79 & 152,74 \\
$29 / 06 / 2013$ & 23,93 & 149,85 \\
$16 / 08 / 2013$ & 23,96 & 149,85 \\
$01 / 09 / 2013$ & 23,88 & 144,08 \\
$19 / 10 / 2013$ & 23,58 & 133,45 \\
$08 / 02 / 2014$ & 22,62 & 109,27 \\
$28 / 03 / 2014$ & 22,57 & 131,12 \\
$02 / 07 / 2014$ & 22,32 & 121,72 \\
$10 / 01 / 2015$ & 19,48 & 67,80 \\
$11 / 02 / 2015$ & 20,12 & 94,14 \\
$04 / 05 / 2016$ & 23,50 & 133,19 \\
$07 / 07 / 2016$ & 24,41 & 155,11 \\
$13 / 07 / 2017$ & 24,12 & 137,06 \\
$02 / 05 / 2018$ & 24,00 & 151,68 \\
$21 / 01 / 2019$ & 23,51 & 117,44 \\
$14 / 06 / 2019$ & 24,13 & 158,28 \\
$01 / 08 / 2019$ & 24,25 & 155,90 \\
$18 / 09 / 2019$ & 24,13 & 142,25 \\
$04 / 10 / 2019$ & 24,19 & 134,48 \\
$21 / 11 / 2019$ & 23,62 & 112,71 \\
$07 / 12 / 2019$ & 23,61 & 113,46 \\
\hline \hline
\end{tabular}

Fonte: Elaborado pelos autores 
Figura 5 - Regressão não-linear dos valores das áreas estimadas pelo índice NDWI e os

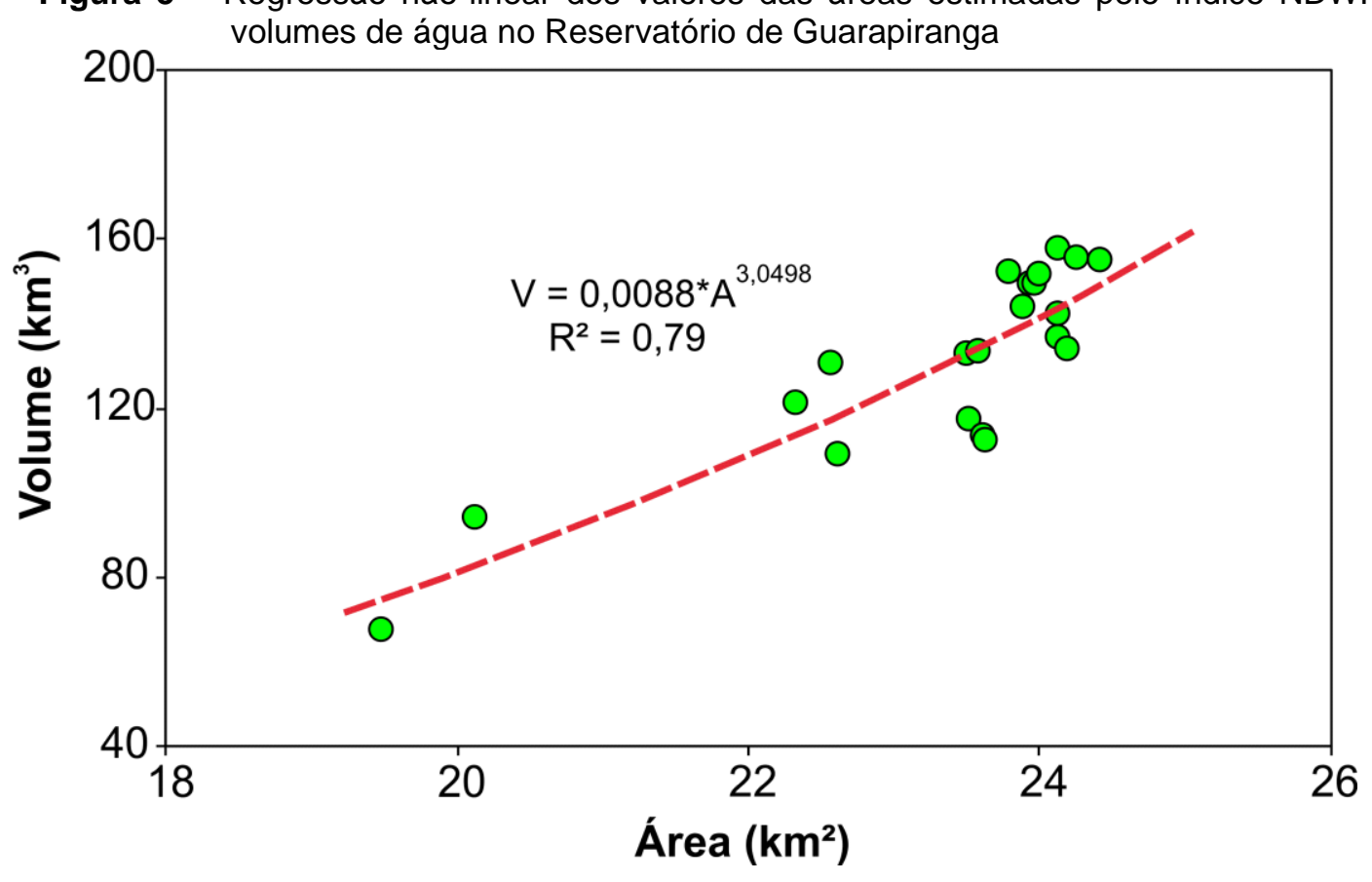

Fonte: Elaborado pelos autores

Para avaliar a adequabilidade do modelo de Lehner et al. (2011), foram realizadas estimativas de volume a partir da Equação 3, que produziram valores 4,4 a 8,3 vezes maiores que vezes o volume real do reservatório (Figura 6). Este fato reforça a inviabilidade de se utilizar este modelo na área de estudo.

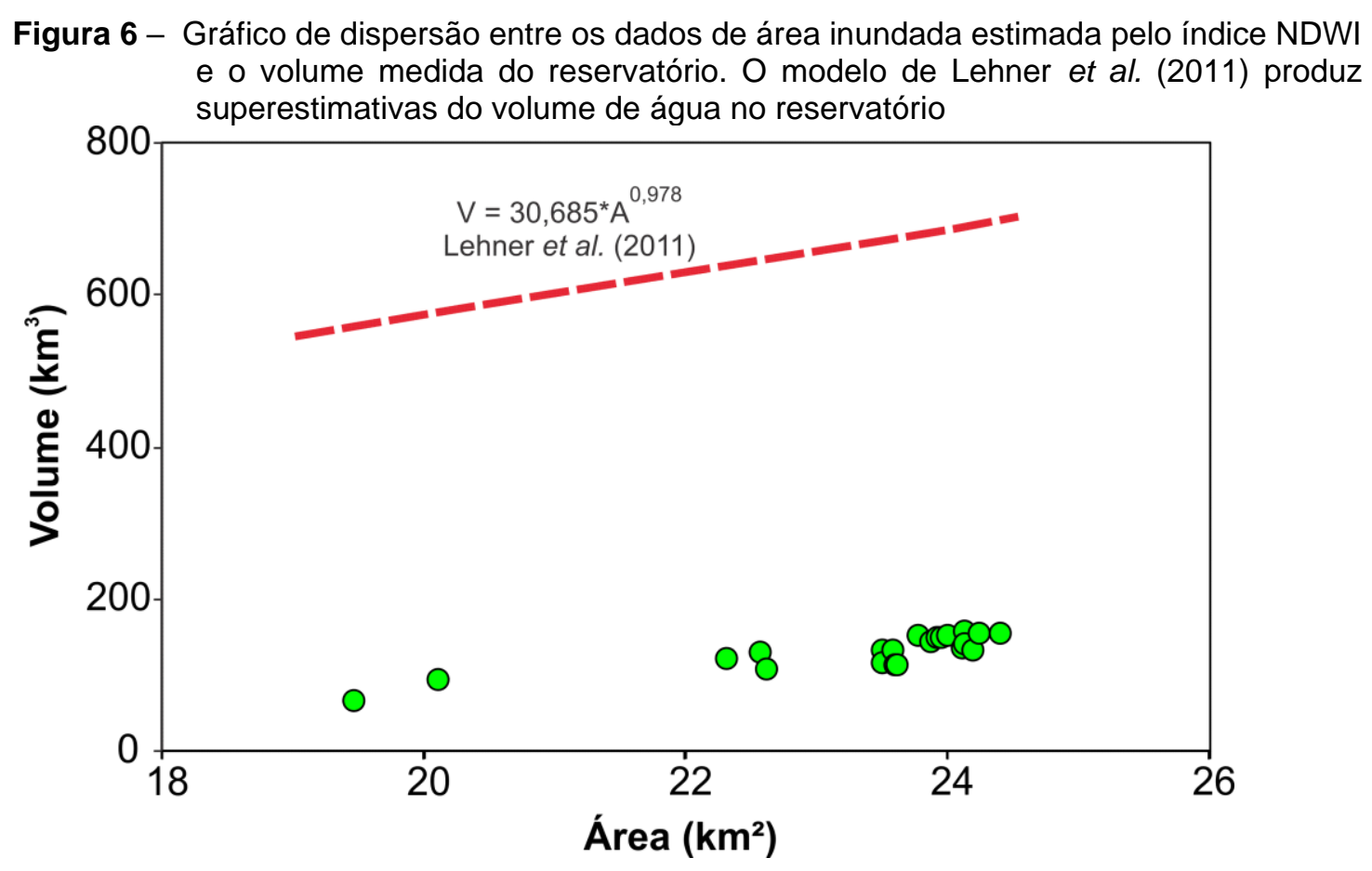

Fonte: Elaborado pelos autores 
A espessura média da lâmina d'água (h) pode ser obtida dividindo o volume de água armazenada pela área coberta por água. A partir dessa relação é possível construir uma curva do volume em função da espessura da lâmina d'água (Figura 7), que representa uma relação análoga à função cota-volume, metodologia usualmente utilizada para determinação dos volumes de água armazenada. Assim, foi determinado a relação h-volume, de acordo com a Equação 5 e verificado que, quando a água ocupa a capacidade máxima da represa, a espessura média da lâmina d'água é de 6,70 metros.

$V=10,064 * h^{1,488}$

Figura 7 - Relação entre a espessura média da lâmina d'água (h) e o volume de água armazenada na Represa de Guarapiranga. Os valores de $\mathrm{h}$ foram obtidos a partir da divisão do volume estimado do reservatório dividido pela área inundada

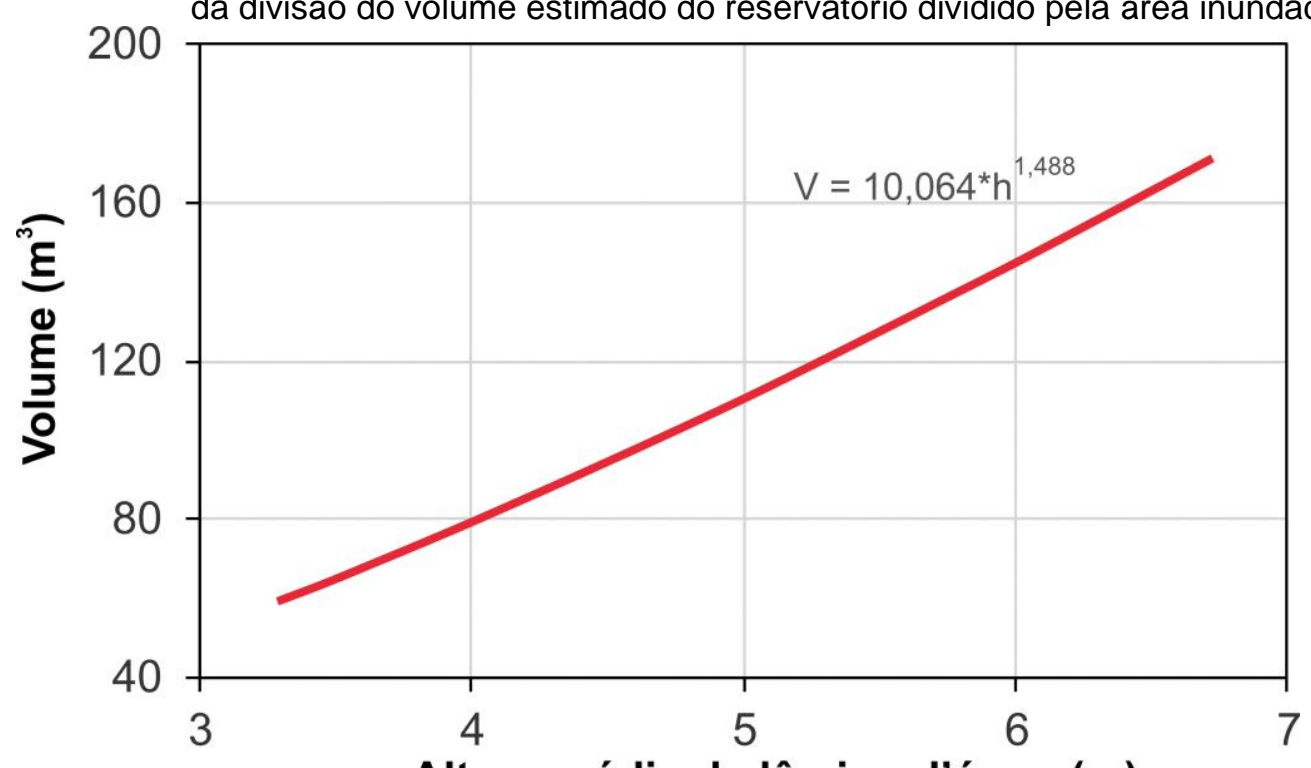

Altura média da lâmina d'água $(\mathrm{m})$

Fonte: Elaborado pelos autores

\section{DISCUSSÃO}

As técnicas de sensoriamento remoto representam ferramentas com elevado potencial para o monitoramento e o gerenciamento de recursos hídricos superficiais, particularmente em regiões com escassez de informações, em razão de sua eficiência, baixo custo e facilidade operacional. A despeito desta potencialidade, as técnicas de sensoriamento remoto têm sido raramente empregadas para auxiliar na gestão dos recursos hídricos superficiais no Brasil. Por esse motivo, o presente 
trabalho buscou demonstrar a aplicação das técnicas de sensoriamento remoto como subsídio à avaliação quantitativa de água em superfície. Acrescenta-se, ainda, que a grande maioria dos modelos área-volume foram estabelecidos para reservatórios de grande porte (centenas de $\mathrm{Km}^{2}$ ), existindo uma carência de informações relacionadas a reservatórios de pequeno porte, como é o caso da Represa de Guarapiranga.

Diante da potencialidade do sensoriamento remoto para monitoramento dos volumes de água armazenados, o emprego da metodologia aqui aplicada possibilita a realização de avaliações quantitativas do volume de água disponível onde o monitoramento é conduzido esporadicamente ou em locais remotos e com acesso é bastante restrito.

Em teoria, o índice MNDWI, proposto por Xu (2006), apresenta melhores resultados do que aqueles obtidos a partir do índice NDWI, proposto por McFeeters (1996). O ajuste da Equação 2 aos dados de área estimados a partir do cálculo do índice NDWI e dos volumes no reservatório para a obtenção da relação área-volume para a Represa de Guarapiranga, produziu um coeficiente de determinação $\left(R^{2}\right)$ de 0,79 (Figura 4), indicando uma forte correspondência entre estes parâmetros. Assim, pode-se afirmar que o NDWI produziu resultados bastante representativos para a represa estudada.

Salienta-se que a resolução espacial de $30 \mathrm{~m}$ do Landsat-8 impõe restrições quanto à sua potencialidade em reservatórios com áreas reduzidas, onde as variações de área coberta por água são menores. Nesses casos, é recomendável o emprego de satélites com maior resolução espacial.

A determinação do volume pelo modelo global proposto por Lehner et al. (2011) mostrou-se inviável para a Represa Guarapiranga, apresentando resultados discrepantes. Tal inconsistência pode estar relacionada ao fato de esse modelo ter sido desenvolvido para reservatórios de grande porte. Dessa forma, em reservatórios de pequeno porte é necessária a elaboração de modelos empíricos locais como aqui apresentado.

\section{CONCLUSÕES}

O presente estudo reforça a potencialidade das técnicas de sensoriamento remoto para estimativas do volume de água armazenadas em reservatórios. Os resultados indicam que as estimativas da área coberta por água na Represa 
Guarapiranga a partir do cálculo do índice NDWI, empregando imagens do satélite Landsat-8 OLI, produzem resultados consistentes. Assim, a metodologia alternativa aqui apresentada presta-se ao monitoramento dos volumes de água armazenada nesse reservatório. Adicionalmente, os modelos baseados em área-volume globais (LEHNER et al., 2011) produzem resultados pouco representativos para reservatórios de pequeno porte, como a Represa de Guarapiranga, que exigem a elaboração de modelos empíricos locais.

\section{REFERÊNCIAS}

$\mathrm{CAI}$, Xiaobin et al. Remote sensing of the water storage dynamics of large lakes and reservoirs in the Yangtze River Basin from 2000 to 2014. Scientific Reports, v. 6, p. 36405, 2016. https://doi.org/10.1038/srep36405

CHAO, Benjamin F.; WU, Y. H.; LI, Y. S. Impact of artificial reservoir water impoundment on global sea level. Science, v. 320, n. 5873, p. 212-214, 2008. Doi:

https://doi.org/10.1126/science.1154580

CUSTÓDIO, Vanderli. A crise hídrica na região metropolitana de São Paulo (2014-

2015). GEOUSP: Espaço e Tempo (Online), v. 19, n. 3, p. 445-463, 2015.

https://doi.org/10.11606/issn.2179-0892.geousp.2015.102136

DEUTSCH, Eliza S.; ALAMEDDINE, Ibrahim. Hindcasting eutrophication and changes in temperature and storage volume in a semi-arid reservoir: a multi-decadal Landsat-based assessment. Environmental monitoring and assessment, v. 191, n. 1, p. 41, 2019. https://doi.org/10.1007/s10661-018-7180-7

GAO, Huilin; BIRKETT, Charon; LETTENMAIER, Dennis P. Global monitoring of large reservoir storage from satellite remote sensing. Water Resources Research, v. 48, n. 9, 2012. https://doi.org/10.1029/2012WR012063

GUPTA, R. P.; BANERJI, S. Monitoring of reservoir volume using LANDSAT data. Journal of Hydrology, v. 77, n. 1-4, p. 159-170, 1985. https://doi.org/10.1016/0022-1694(85)90204-5

HADDELAND, Ingjerd; SKAUGEN, Thomas; LETTENMAIER, Dennis P. Anthropogenic impacts on continental surface water fluxes. Geophysical Research Letters, v. 33, n. 8, 2006. https://doi.org/10.1029/2006GL026047

LEHNER, Bernhard; DÖLL, Petra. Development and validation of a global database of lakes, reservoirs and wetlands. Journal of Hydrology, v. 296, n. 1-4, p. 1-22, 2004. https://doi.org/10.1016/j.jhydrol.2004.03.028

LEHNER, Bernhard et al. Global reservoir and dam (grand) database. Technical Documentation, Version, v. 1, p. 1-14, 2011. https://doi.org/10.1016/j.jhydrol.2004.03.028

LIEBE, J.; VAN DE GIESEN, N.; ANDREINI, Marc. Estimation of small reservoir storage capacities in a semi-arid environment: A case study in the Upper East Region of Ghana. Physics and Chemistry of the Earth, Parts A/B/C, v. 30, n. 6-7, p. 448-454, 2005. https://doi.org/10.1016/i.pce.2005.06.011 
LU, Shanlong et al. Lake water volume calculation with time series remote-sensing

images. International Journal of Remote Sensing, v. 34, n. 22, p. 7962-7973, 2013. Doi: https://doi.org/10.1080/01431161.2013.827814

MANCUSO, Pedro Caetano Sanches. O reuso da água e sua possibilidade na Região Metropolitana de São Paulo. 1992. Tese de Doutorado. Universidade de São Paulo.

MCDONALD, Kristen; BOSSHARD, Peter; BREWER, Nicole. Exporting dams: China's hydropower industry goes global. Journal of Environmental Management, v. 90, p. S294S302, 2009. https://doi.org/10.1016/j.jenvman.2008.07.023

MCFEETERS, Stuart K. The use of the Normalized Difference Water Index (NDWI) in the delineation of open water features. International journal of remote sensing, v. 17, n. 7, p. 1425-1432, 1996. https://doi.org/10.1080/01431169608948714

NELLIS, M. Duane; HARRINGTON JR, John A.; WU, Jaiping. Remote sensing of temporal and spatial variations in pool size, suspended sediment, turbidity, and Secchi depth in Tuttle Creek Reservoir, Kansas: 1993. Geomorphology, v. 21, n. 3-4, p. 281-293, 1998. https://doi.org/10.1016/S0169-555X(97)00067-6

RAN, Lishan; LU, X. X. Delineation of reservoirs using remote sensing and their storage estimate: an example of the Yellow River basin, China. Hydrological Processes, v. 26, n. 8, p. 1215-1229, 2012. https://doi.org/10.1002/hyp.8224

SABESP. CHESS - Crise hídrica, estratégia e soluções da Sabesp para a Região Metropolitana de São Paulo. Sabesp. 2015

SABESP. Avaliação da Disponibilidade Hídrica de Mananciais para utilização na RMSP. Revisão e Atualização do Plano Diretor de Abastecimento de Água da Região Metropolitana de São Paulo - RMSP (PDAA). Relatório Parcial RP02. Rev. 05. 2016.

SHIKLOMANOV, Igor A. The world's water resources. In: International symposium to commemorate the. 1991. p. 93-105.

TIMPE, Kelsie; KAPLAN, David. The changing hydrology of a dammed Amazon. Science Advances, v. 3, n. 11, p. e1700611, 2017. https://doi.org/10.1126/sciadv.1700611

VAN BEMMELEN, C. W. T. et al. Determining water reservoir characteristics with global elevation data. Geophysical Research Letters, v. 43, n. 21, p. 11,278-11,286, 2016. https://doi.org/10.1002/2016GL069816

WISSER, Dominik et al. Beyond peak reservoir storage? A global estimate of declining water storage capacity in large reservoirs. Water Resources Research, v. 49, n. 9, p. 5732-5739, 2013. https://doi.org/10.1002/wrcr.20452

XU, Hanqiu. Modification of normalised difference water index (NDWI) to enhance open water features in remotely sensed imagery. International journal of remote sensing, v. 27, n. 14, p. 3025-3033, 2006. https://doi.org/10.1080/01431160600589179

ZARFL, Christiane et al. A global boom in hydropower dam construction. Aquatic Sciences, v. 77, n. 1, p. 161-170, 2015. https://doi.org/10.1007/s00027-014-0377-0 